\title{
Periodontal Bone Regeneration and the Er,Cr:YSGG Laser: A Case Report
}

\author{
Douglas N. Dederich Cert. Perio
}

\author{
Room 5-531 ECHA, Department of Dentistry, Faculty of Medicine and Dentistry, University of Alberta, Edmonton, Al- \\ berta, T6G 1C9; Canada
}

\begin{abstract}
Background: Traditional methods of regenerating bone in periodontal bone defects have been partially successful and have involved numerous protocols and materials. More recently, it has been proposed that Er,Cr:YSGG laser energy may also be beneficial in the treatment of periodontal pockets, particularly in the regeneration of bone lost due to periodontal disease.

Case Description: The purpose of this paper is to present a case report of the Er,Cr:YSGG laser being used to conservatively treat a recalcitrant periodontal pocket in the presence of a periodontal bone defect and that resulted in successful resolution of the pocket and significant radiographic bone fill at the 1 year recall visit.

Clinical Implications: This protocol using the Er,Cr:YSGG laser for the treatment of periodontal loss of attachment and periodontal bone loss may represent a less invasive alternative than traditional open-flap periodontal surgery or the intrasulcular use of other more penetrating laser wavelengths.
\end{abstract}

Keywords: Alveolar Bone, Bone, Laser Surgery, Lasers, Periodontal Pocket, Periodontitis.

\section{INTRODUCTION}

Traditional methods of regenerating bone in periodontal bone defects have been partially successful and have involved numerous protocols and materials. Many of these protocols involve debridement of the bone defect, planing of the adjacent root surface and the placement of membranes and/or bone graft materials. [1] Other factors hypothesized to have influence on the degree of bone fill obtained in such defects include trauma from occlusion, [2] resident bacterial flora and systemic health [3] and smoking. [4]

It has been proposed that Er,Cr:YSGG laser energy may be beneficial in the treatment of periodontal pockets. [5] This laser has been cleared for marketing by the FDA $510 \mathrm{~K}$ process for soft and hard tissue application, including gain of new attachment, [6] the removal of calculus on root surfaces [7] and for use on bone [8]. In clinical trials, this laser has been shown to provide either equivalent or superior results when compared to mechanical scaling and root planing. [9] Due to its very shallow penetration in tissue, the thermal risk to deeper tissues is minimal. [10]

The purpose of this paper is to present a case report of the Er,Cr:YSGG laser being used to conservatively treat a recalcitrant periodontal pocket in the presence of a bone defect and that resulted in successful resolution of the pocket and significant radiographic bone fill at the 1 year recall visit.

*Address correspondence to this author at the Room 5-531 ECHA, Department of Dentistry, Faculty of Medicine and Dentistry, University of Alberta, Edmonton, Alberta, T6G 1C9; Canada, Tel: 780-492-6256;

Fax: 780-492-7536; Email: Dederich@ualberta.ca

\section{MATERIALS AND METHODOLOGY}

The patient was diagnosed as having advanced chronic periodontitis at the initial examination visit. After a discussion of the treatment options, traditional mechanical nonsurgical initial therapy was recommended and accepted by the patient. This nonsurgical initial therapy consisted of fullmouth scaling and root planing followed by a re-evaluation examination 6 weeks later. No systemic or local antibiotics were used during this initial therapy. Further, no occlusal adjustment was performed.

The re-evaluation examination revealed substantial pocket reduction with the exception of the maxillary left second molar area, where a residual $8 \mathrm{~mm}$ probing depth was noted that was associated with radiographic evidence of a severe angular bone defect on the mesial of the left second maxillary molar (Fig. 1). Er,Cr:YSGG Laser MinimallyInvasive Surgery (LMIS) was then recommended as a more definitive therapy. LMIS was performed in a conservative fashion, limiting the area of surgery to the area of the residual pocketing and bone defect. The protocol for Er,Cr:YSGG LMIS was similar to that described in Dyer and Sung (2012) [11] and is shown in Table 1. Local anesthesia was administered and a gingival trough down to the crest of bone was made in the area of the pocket using the Er,Cr:YSGG laser to provide improved access to the root surface associated with the bone defect. No flap was raised and the bone defect was not subjected to open-flap debridement. Mechanical debridement of the root surface was then performed using ultrasonics, slow-speed rotary diamond burs and hand instruments. The root surface and intra-pocket soft tissue were then exposed to a final regimen of laser energy with a side- 


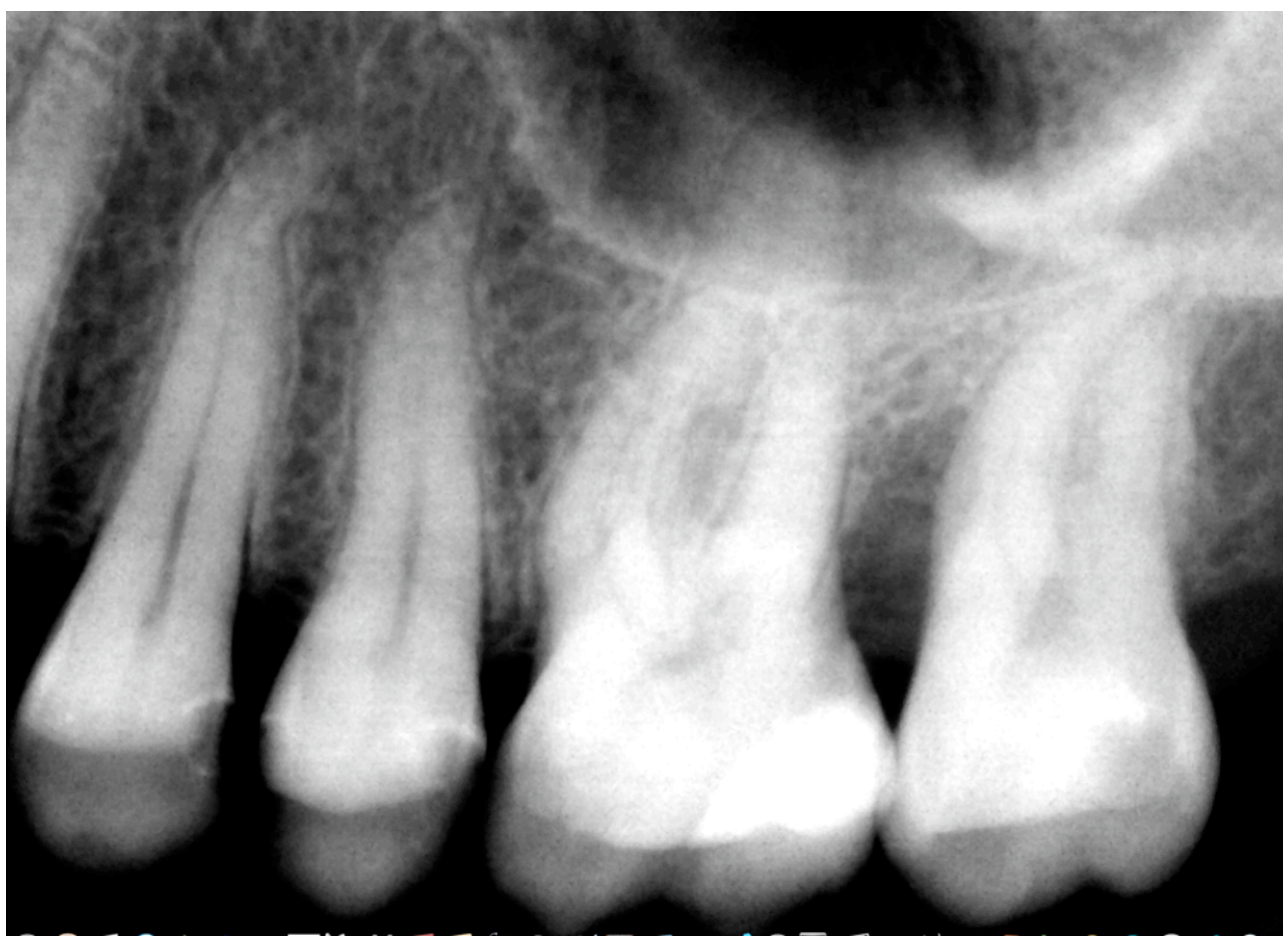

Fig. (1). Pre-operative radiograph demonstrating radiographic evidence of an angular bone defect on the mesial of the maxillary left second molar.

Table 1. Er,Cr:YSGG Laser Minimally-Invasive Surgery Protocol

\begin{tabular}{|l|}
\hline Local Anesthesia \\
\hline \hline $\begin{array}{l}\text { Gingival Troughing with Er,Cr:YSGG laser down to crest of bone in areas of pocketing. Exposure parameters: Power 1.5 Watts; Pulse Repetition Rate } 30 \\
\text { pps; } 15 \% \text { Water; 11\% Air }\end{array}$ \\
\hline Mechanical Root Debridement \\
\hline $\begin{array}{l}\text { Final decontamination of root surface with Er,Cr:YSGG laser using side-firing tip. Exposure parameters: Power 1 Watt; Pulse Repetition Rate 50pps; } 15 \% \\
\text { Water; } 11 \% \text { Air }\end{array}$ \\
\hline Tissue pressed back against root surface and sealed with cyanoacrylate adhesive \\
\hline
\end{tabular}

firing tip that directed the majority of the energy in a direction radial to the long axis of the fiber. Finally, the soft tissue was gently pressed against the root surface and sealed with cyanoacrylate tissue adhesive.

The patient was seen at 2 weeks and reported being comfortable. Throughout the next year the patient was seen for periodontal recall visits at 3-month intervals. At 12 months a re-evaluation examination was performed that included charting and a periapical radiograph of the surgical area.

\section{RESULTS}

At the 1-year re-evaluation examination, probing depths in the defect area had decreased from $8 \mathrm{~mm}$ to $2 \mathrm{~mm}$. The periapical radiograph (Fig. 2) showed evidence of complete bone fill. The patient also reported being asymptomatic.

\section{DISCUSSION}

Lasers currently used in the treatment of periodontal disease include the Nd:YAG, diode (at several wavelengths), $\mathrm{CO} 2$, and $\mathrm{Er}, \mathrm{Cr}$ :YSGG lasers. Due in part to their different wavelengths, their interactions with tissue are different, complicating the comparisons between their use in this application. Of these, the only family of lasers that have FDA clearance for use on hard tissue are the Er:YAG and Er,Cr:YSGG lasers. [12]. The shallow penetration seen with these two wavelengths result in a predominantly surface effect in comparison to the deeper penetrating wavelengths of the Nd:YAG and diode lasers. The ability to remove soft tissue, calculus and bone sets the erbium laser family apart from the other laser wavelengths when considering intrapocket use in the treatment of periodontal disease [12]. The shallow penetration conceivably minimizes the risk of deep thermal damage leading to bone and soft tissue necrosis that can occur with over-exposure of the more penetrating wavelengths such as the Nd:YAG and diode lasers. While the NdYAG and diode lasers do not have FDA clearance for use on hard tissue, it is likely that hard tissues are nevertheless exposed to these laser wavelengths during intrasulcular use.

Claims of laser-induced pocket reduction and bone regeneration are not new in the marketplace and remain controversial $[13,14]$. Hypothesizing potential mechanisms for these claims seems moot until satisfactory evidence from 


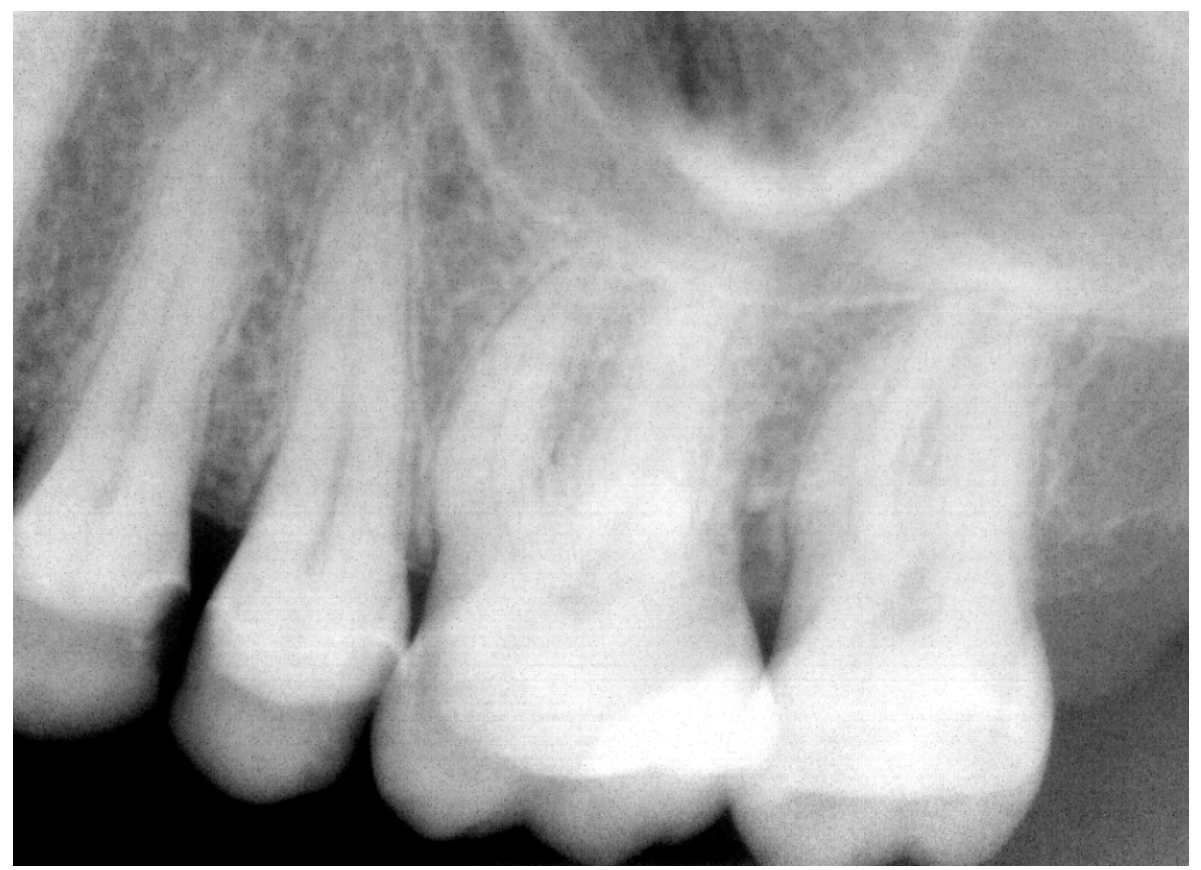

Fig. (2). One-year post-surgical radiograph showing complete radiographic bone fill on the mesial of the maxillary left second molar. Associated probing depths were $3 \mathrm{~mm}$ or less.

independent clinical trials convincingly demonstrate this effect. Standards of evidence for such laser claims have been published by the ADA and provide guidance in this area. [15] The literature seems to suggest that there is no evidence to support the superiority of the Nd:YAG laser over conventional modalities of periodontal therapy. [16] The erbium lasers, when used adjunctively in conjunction with conventional scaling and root planing, have also demonstrated mixed results. In one systematic review, only two of five randomized clinical trials reported a significant improvement of periodontal indices when the Er:YAG laser was used in addition to conventional scaling and root planing. Further, the meta-analysis revealed no significant differences for any investigated parameters at six and 12 months. [9] A later systematic review corroborated this result. [17] However, in this systematic review, the authors caution that due to the "significant heterogeneity, a high risk of bias in three of the five included studies, and methodological shortcomings, the results of their review should be considered with great caution." Interestingly, recent clinical evidence suggests the Er,Cr:YSGG laser, when used after conventional scaling and root planing, produces a superior result in pockets of $6 \mathrm{~mm}$ or less. [18] In this context, in-vitro evidence of bacterial reduction of a contaminated root surface of up to $500 \mu \mathrm{m}$ in depth after Er,Cr:YSGG laser exposure [19] suggests a possible mechanism to explain this beneficial result.

It is interesting that this case produced apparent bone regeneration without occlusal adjustment or the use of systemic antibiotics. Potential co-factors that may have had an influence over the bone regeneration seen in this case would include the mechanical debridement of the root surface and any of the potential laser effects. These effects would hypothetically include a neutralizing effect of endotoxin on the root surface $[20,21]$, calculus removal $[22,23]$ root disinfection [19] and/or an as yet undemonstrated biostimulatory effect of the Er,Cr:YSGG on the subsequent healing.
In view of the pocket reduction and bone regeneration seen in this case, it may be that this protocol has value as an alternative to traditional periodontal surgery and bone grafting techniques. Further, it appears less invasive than the LANAP technique $[24,25]$ that utilizes the deeper penetrating Nd:YAG laser and also recommends systemic antibiotics and occlusal adjustment as part of the protocol. Further research is required to test the hypothetical utility of Er,Cr:YSGG LMIS to enhance periodontal bone regeneration within independent clinical trials.

\section{CONCLUSION}

Successful pocket reduction and bone regeneration was achieved using Er,Cr:YSGG Laser Minimally-Invasive Surgery (LMIS). This protocol using the Er,Cr:YSGG LMIS may represent a less invasive modality than traditional periodontal surgery or the use of other more penetrating laser wavelengths for the intra-pocket treatment of periodontal disease. The specific contribution of the Er,Cr:YSGG laser to the clinical result seen in this case remains undetermined as that can only be determined by corroborative independent clinical trials of appropriate design.

\section{CONFLICT OF INTEREST}

The authors confirm that this article content has no conflicts of interest.

\section{ACKNOWLEDGEMENTS}

Declared none.

\section{REFERENCES}

[1] Wang HL, Greenwell H, Florellini J, et al. Periodontal regeneration. J Periodontol 2005; 76(9): 1601-22.

[2] Weston P, Yaziz YA, Moles DR, Needleman I. Occlusal interventions for periodontitis in adults. Cochrane Database Syst Rev 2008; 3: CD004968. 
[3] Position paper: The pathogenesis of periodontal diseases. research, science and therapy committee of the American Academy of Periodontology. J Periodontol 1999; 70: 457-70.

[4] Position paper: tobacco use and the periodontal patient. research, science and therapy committee of the American Academy of Periodontology. J Periodontol 1999; 70(11): 1419-27.

[5] American Academy of Periodontology statement on the efficacy of lasers in the non-surgical treatment of inflammatory periodontal disease. J Periodontol 2011; 82(4): 513-4

[6] FDA 510(k) Clearances: K011041, K013908, K030523, K083927, K101658 FDA.

[7] FDA 510(k) Clearance K091746.

[8] FDA 510(k) Clearances K090181, K101658.

[9] Niederman R. Are lasers as effective as scaling for chronic periodontitis? Evid Based Dent 2011; 12(3): 80-1.

[10] Iwai K, Shi YW, Endo M, et al. Penetration of high-intensity Er:YAG laser light emitted by IR hollow optical fibers with sealing caps in water. Appl Opt 2004; 43(12): 2568-71.

[11] Dyer B, Sung EC. Minimally invasive periodontal treatment using the Er,Cr:YSGG Laser. A 2-year retrospective preliminary clinical study. Open Dent J 2012; 6: 74-8.

[12] ADA Council on scientific affairs. ADA statement on lasers in dentistry 2009; Available from: http://www.ada.org/1860.aspx.

[13] Cobb CM. Lasers in periodontics: a review of the literature. J Periodontol 2006; 77(4): 545-64.

[14] Karlsson MR, Diogo Lofgren CI, Jansson HM. The effect of laser therapy as an adjunct to non-surgical periodontal treatment in subjects with chronic periodontitis: a systematic review. J Periodontol 2008; 79(11): 2021-8.

[15] American Dental Association Technical Report No. 110: standard procedures for the assessment of laser-induced effects on oral hard and soft tissues; a technical report prepared by the American Dental Association and registered wtih ANSI 2008.
[16] Slot DE, Kranendonk AA, Paraskevas S, Van Der Weijden F. The effect of a pulsed Nd:YAG laser in non-surgical periodontal therapy. J Periodontol 2009; 80(7): 1041-56.

[17] Sgolastra F, Petrucci A, Gatto R, Monaco A. Efficacy of Er:YAG laser in the treatment of chronic periodontitis: systematic review and meta-analysis. Lasers Med Sci 2012; 27(3): 661-73.

[18] Kelbauskiene S, Baseviciene N, Goharkhay K, Moritz A, Machiulskiene V. One-year clinical results of Er,Cr:YSGG laser application in addition to scaling and root planing in patients with early to moderate periodontitis. Lasers Med Sci 2011;26(4): 44552.

[19] Franzen R, Esteves-Oliveira M, Meister J. Decontamination of deep dentin by means of erbium, chromium:yttrium-scandiumgallium-garnet laser irradiation. Lasers Med Sci 2009; 24(1): 7580 .

[20] Giannelli M, Pini A, Formigli L, Bani D. Comparative in vitro study among the effects of different laser and LED irradiation protocols and conventional chlorhexidine treatment for deactivation of bacterial lipopolysaccharide adherent to titanium surface. Photomed Laser Surg 2011; 29(8): 573-80.

[21] Folwaczny M, Aggstaller H, Mehi A, Hickel R. Removal of bacterial endotoxin from root surface with Er:YAG laser. Am J Dent 2003; 16(1): 3-5.

[22] Eberhard J, Ehlers H, Falk W, Acil Y, Albers HK, Jepsen S. Efficacy of subgingival calculus removal with Er:YAG laser compared to mechanical debridement: an in situ study. J Clin Periodontol 2003; 30(6): 511-8.

[23] Krause F, Braun A, Brede O, Eberhard J, Frentzen M, Jepsen S. Evaluation of selective calculus removal by a fluorescence feedback-controlled Er:YAG laser in vitro. J Clin Periodontol 2007; 34(1): 66-71.

[24] Gregg RH, McCarthy DK. Laser ENAP for periodontal bone regeneration. Dent Today 1998; 17(5): 88-91.

[25] Gregg RH and McCarthy DK. Laser ENAP for periodontal ligament regeneration. Dent Today 1998; 17(11): 86-9.

(C) Douglas N. Dederich Cert. Perio; Licensee Bentham Open.

This is an open access article licensed under the terms of the Creative Commons Attribution Non-Commercial License (http://creativecommons.org/licenses/by-nc/3.0/) which permits unrestricted, non-commercial use, distribution and reproduction in any medium, provided the work is properly cited. 